\title{
Characteristics of materials for microwave devices
}

\author{
V R K MURTHY*, K C JAMES RAJU* and B VISWANATHAN ${ }^{+}$ \\ *Department of Physics, 'Department of Chemistry, Indian Institule of Technology. \\ Madras 600036 . India
}

Abstract. The characteristics of materials like ferrites, garnets, ferroelectrics, temperaturecompensated dielectrics and copper-coated PTFE-based composites. extensively used in microwave devices are discussed.

Keywords. Microwaves; ferrites; garnets; ferroelectrics; dielectric resonators; metallized PTFE.

\section{Introduction}

The transmission lines for the guided propagation of electromagnetic waves in the microwave frequency range ( 1 to $100 \mathrm{GHz}$ ) are waveguides and microwave integrated circuits (MICs). The waveguide components/devices are bulky and expensive but can carry high power whereas MICs show their versatility in low power, light weight and miniaturized microwave systems. The development of these waveguide-based components and MICs depends upon the availability of materials with specilic characteristics. Hence the physicochemical properties of such materials have an impact on microwave technology. In this paper, we describe a few sets of such microwave materials and their characteristics which make them suitable for microwave devices.

\section{Microwave materials and characteristics}

The primary requirements of a microwave material are low d.c. conductivity, low dielectric and magnetic losses, and temperature-independent dielectric or magnetic properties. Some of the materials that satisfy these requirements are ferrites, garnets, ferroelcctrics and temperature-compensated dielectrics which are ceramic materials and copper clad composites based on PTFE which are used as substrates for MICs.

\subsection{Ferrites and garnets}

Spinel ferrites are a class of magnetic materials with a general formula $\mathrm{MFe}_{2} \mathrm{O}_{4}$ ( $M=$ a divalent metal). $M$ can be replaced with two divalent metals with the chemical formula $\mathrm{M}_{1-x} \mathrm{M}_{x}^{\prime} \mathrm{Te}_{2} \mathrm{O}_{4}$. The parameter $x$ varies from 0 to 1 , thus changing the physical parameters according to device requirements. $\mathrm{M}$ can also be replaced with monovalent and trivalent metals and lithium and lithium zinc ferrites belong to such a family (Baba et al 1971): Garnets are another class of materials with the cations being rare earths and iron. An example of such a family of compounds is yttrium iron garnet $\left(\mathrm{Y}_{3} \mathrm{Fe}_{5} \mathrm{O}_{12}\right)$. One can prepare garnets and ferrite powder materials using conventional ceramic method and this is most widely used by industrial organizations.

A comparison of fcrrite and garnet compounds is given in table 1. Various techniques 
Table I. Comparison of the characteristics of ferrites and garncts.

\begin{tabular}{ll}
\hline Fetrites & Garnets \\
\hline Variable resistivity & Very high resistivity \\
Saturation magnetization variable & Low \\
Curic temperatture wriable & High \\
Cocrcivity low & Low \\
Stable compounds & Stable compounds \\
Can he prepured al low & Very high temperatutes \\
$\quad$ temperatures also & only \\
Strueture cubic & Cubic \\
Partially filled structure & Completely lilled \\
& structure \\
Line-width bigh & Low \\
Microwave losses medium & Low \\
Dielectric constant high & High \\
Low cost & High cost
\end{tabular}

Table 2. Typical speciffcation of a microwave material (fernite) for use as isolacor/attenuator.

\begin{tabular}{lc}
\hline Saturation megnetization & $200-2000$ Gauss \\
Microwave loss tangent & $1 \times 10^{-4}$ \\
Coercivity & $10 e$ \\
Line-width & $1-100 \mathrm{e}$ \\
BH squareness ratio & 0.75 \\
Dielectric congrant & 15 \\
\hline
\end{tabular}

Table 3. Typical characteristics of lithium ferrite.

\begin{tabular}{|c|c|}
\hline Resistivity & $8 \times 10^{5} \mathrm{ohm}-\mathrm{cm}$ \\
\hline Saluration nagnelization & 3745 Gauss \\
\hline Resonance line-width & $300 e$ \\
\hline Squareness ratio & 0.95 \\
\hline Curie temperature & $890 \mathrm{~K}$ \\
\hline Microwelve loss & $1 \times 10^{-4}$ \\
\hline Dielectric contilint & 10 \\
\hline
\end{tabular}

are currently employed in characterizing these materials at microwave frequency. However, the most reliable method 'cavity perturbation technique' has been used for the inicrowa ve characterization of these materials and the details were given by Murthy and Raman (1989). The specifications of a ferrite material for isolator/attenuator appications are given in table 2 and some characteristics of lithium ferrite for such devices are given in table 3 .

\subsection{Ferroelectrics}

Ferroelectrics are electrical analogues of ferromagnets displaying Curie-Weiss law in their diclectric constant variation with temperature (Lines and Glass 1977). For 
microwave applications they are used above the Curie temperature ( $\rho_{c}$ ), i.e. in the paraelectric region becausc thesc materials do not exhibit their characteristic hysteresis, piezoeloctric and pyroelectric effects in the paraelectric state but still exhibit large dielectric constant which depends on voltage and temperature with a lower dielectric loss. Majority of the applications utilizing ferroelectrics depend on their large nonlinearity in dielectric constant at a particular temperature above $T_{c}$ either under a de bias or under varying field strength of the microwave power (Horton and Donaldson 1967) A ferroelectric whose $T_{\varepsilon}$ is balow room temperature, having low dielectric loss a! room temperature, exhibiting large noninearity in diefectric constant above $T_{c}$ but dependent on temperature only siuggishly is ideal for microwave applications. Materials like $\mathrm{BaTiO}_{3}, \mathrm{SrTiO}_{3}\left(\mathrm{~Pb}_{\mathrm{x}} \mathrm{Sr}_{1-x}\right) \mathrm{TiO}_{3}$ with $x=0.315,0.35$ and 0.45 . $\left(\mathrm{Ba}_{0.75} \mathrm{Sr}_{0.25}\right) \mathrm{TiO}_{3}$ are used widely in microwave applications. All of them crystaliize in perovskite structure with $T_{*}$ below $393 \mathrm{~K}$. They are used in the ceramic form and have resistivities of the order of $10^{11}$ to $10^{13} \Omega \mathrm{m}$.

When a de bias voltage is applied both the dielectric constant and the loss of a ferroelectric will decrease. The nonlinear dielectric properties enable them to be used in microwave fi]ters, limiters, phase shifters, switches, mixers and modulators and as the active element for microwave parametric amplifiers/oscillators, harmonic generators and electromagnetic shock wave generators.

The advent of ferroelectric thin films will help as it decreases the amount of do voltage required to bring in sufficient change in the dielectric constant (Das 1967). Ferroelectrics generally have retaxation in or around the roicrowave region. They can be used only at frequencies far away from the relaxation region. Ferroelectrics are characterized using coaxial cavities at smaller microwave frequencies and by a transmission technique at higher frequencies. However, data on the large signal microwave dielectric properties of ferroelectrics are scarce. Table 4 contains the data of a few ferroelectrics used in microwave applications. Ualess otherwise specified, the materials given in this table were employed in ceramic form (Das 1964).

Table 4. Characteristies of some ferroelectrics used in microwave devices.

\begin{tabular}{|c|c|c|c|c|c|}
\hline \multirow[b]{2}{*}{ Milterjal } & \multirow[b]{2}{*}{$\varepsilon$} & \multirow[b]{2}{*}{$\tan \delta$} & \multicolumn{2}{|c|}{ Measured at } & \multirow[b]{2}{*}{$\begin{array}{c}\text { Curic } \\
\left.\text { temp. ( }{ }^{\circ} \mathrm{C}\right)\end{array}$} \\
\hline & & & $\begin{array}{c}\text { Irequency } \\
\text { (GHz) }\end{array}$ & $\begin{array}{l}\text { temp. } \\
\left({ }^{\circ} \mathrm{C}\right)\end{array}$ & \\
\hline Single crystal $\mathrm{BaTlO}_{3}$ & 2000 & $\approx 0.15$ & 240 & 20 & 130 \\
\hline Ceramic $\mathrm{BaTiO}_{3}$ & 600 & $\sim 0.3$ & 30 & 25 & 130 \\
\hline Hot-pressed $\mathrm{Cd}_{2} \mathrm{Nb}_{2} \mathrm{O}_{7}$ & 435 & $0-069$ & 40 & 26 & -88 \\
\hline$\left(\mathrm{Ba}_{0.73} \mathrm{Sr}_{0.27}\right) \mathrm{TiO}_{3}$ & 3350 & $\begin{array}{l}\sim 0 \cdot 16 \\
(22 \mathrm{GHz})\end{array}$ & 124 & 21 & 20 \\
\hline Single crystal $\mathrm{SrTiO}_{3}$ & $\sim 1000$ & 00013 & $7 \cdot 65$ & -150 & -163 \\
\hline$\left(\mathrm{Pb}_{0.31} \mathrm{~s}_{\mathrm{r}_{0.68}}\right) \mathrm{TiO}_{\mathrm{3}}$ & $\$ 475$ & 005 & $\mathrm{l}$ & & 23 \\
\hline$\left(\mathrm{Pb}_{0.35} \mathrm{Sr}_{0-63}\right) \mathrm{TiO}_{3}$ & 5750 & $0-055$ & 02 & $20 \cdot 5$ & \\
\hline$\left(\mathrm{Gt}_{4-43} \mathrm{Sr}_{0-55}\right) \mathrm{TiO}_{3}$ & 4800 & 0.008 & 0.218 & 120 & 116 \\
\hline
\end{tabular}




\subsection{Materials for dielertic resonators}

Dielectric resonators ate used in MICs for frequency control. They are just a ceramic pellet in the form of a parallelopiped or cylindrical disc (Fiedziszko 1986). When a continuous band of mjcrowaye is passed through a dielectric resonator, it will resonate at a fow discrete frequencies determined by the geometry and dimensions of the pellet. Since the eleciromagnetic field can satisly the boundary conditions in more than one mode, one will get a series of rrodes each having different field pattern. The most widely used mode is the $\mathrm{TE}_{011}$ mode. The material used for making dielectric resonators should satisfy the conditions given below (Subba Rao et al 1990):

(a) The dielectric constant stould be high (generally 10 to 100 ), (b) the dielectric loss should be low (tan $\delta=0.0003$ ) and (c) the temperature coefficient of resonant frequency $\tau_{f}$ must be very small $\left(\tau_{f}\right.$ must be less than $\pm 50 \mathrm{ppm}$ ).

is large 8 will aid miniaturization while a low dielectric loss will result in a high $Q$ value. But the value of $\tau_{f}$ depends on both the temperature coefficient of dielectric constant $\left(\tau_{\varepsilon}\right)$ and the coeflicient of thermal expansion $(\alpha)$ since $\tau_{f}=\frac{1}{2} \tau_{x}+x$. Materials with compensating $\tau_{\mathrm{g}}$ and $\alpha$ give low value of $\tau_{f}$. $\tau_{\mathrm{g}}$ depends only on the lattice dynamics of the material while $\alpha$ can be controlled through heat treatments. The materiais should not have any relaxation near the frequency range of interest. The materials which are widely used as DR have peroyskite or perovskile-related structures. But the rolc of secondary phases in DR materials is consioterable. They help in sintering as well as in enhancing the desirable properties.

Dielectric resonators are used in various types of filters and oscillators and as miniature radiating elements in microwave integrated circuits. Coupling to DR is easy and can replace bulky cavity resonators in many applications. Thesc temperaturecompensated diclccirics are characterized in the microwave frequency range using a method popularly known as Courney's (1970) method.

Characteristics of some representative temperature compensated dielectrics are given in table 5 (Nomura 1983; Wakino et al 1984).

\subsection{Copper-cuated PTFE (polytetrafluoroethylene)}

Metallized fluorocatbon polymers (PTFE) with woven of nonwoven glass fibre and with high dielectric constant ceramic fillers offer a combination of properties suitable

Table 5. Typichl temperaturc-compensated dielectrics and their characterislics.

\begin{tabular}{|c|c|c|c|}
\hline Mațcrials & $\varepsilon$ & $Q$ & $\mathrm{pps} / / \mathrm{C}$ \\
\hline $\mathrm{Ba}_{2} \mathrm{Ti}_{4} \mathrm{O}_{20}$ & $39 \cdot 4$ & $3300(9.8 \mathrm{GHz})$ & $\mathfrak{j}$ \\
\hline $\mathrm{BaTi}_{4} \mathrm{O}_{9}$ & 37.8 & $2900\left(9.8 \mathrm{GH}_{2}\right)$ & \\
\hline $\mathrm{Ca}\left(\mathrm{Zr}_{0.985} \mathrm{Ti}_{\mathrm{0}-015}\right) \mathrm{O}_{3}$ & $29 \cdot 0$ & $3300(4 \mathrm{GHz})$ & -23 \\
\hline$\left(\mathrm{Zr}_{1}, \mathrm{Sn}\right) \mathrm{TiO}_{4}$ & $38 \cdot 0$ & $13000(3 \mathrm{GHz})$ & 0 \\
\hline $\mathrm{BuO}-\mathrm{PbO}-\mathrm{Nd}_{2} \mathrm{O}_{3}-\mathrm{TiO}_{2}$ & 880 & $2000(3 \mathrm{GHz})$ & 0 \\
\hline $\mathrm{Ba}\left(\mathrm{Zn}, \mathrm{Ta}_{\mathrm{a}} \mathrm{O}_{3}\right.$ & $29-0$ & $10000(7 \mathrm{GHz})$ & 1 \\
\hline $\mathrm{Ba}(\mathrm{Zn}, \mathrm{Nb}) \mathrm{O}_{3}$ & $41 \cdot 0$ & $9150(9.5 \mathrm{GHz})$ & 31 \\
\hline
\end{tabular}


for applications like microwave antenna (Traut 1980) and microwave integrated circuits (Olyphant and Ball 1970). For these microwave applications, the microwave substrate chosen should meet certain exacting demands like uniform dielectric constant, controiled thickness and low loss (Woermbke 1979). The copper-coated PTFE substrate is most commonly used for this purpose. The substrate was conditioned in sodium hydroxide, acetone and water mixture. The preconditioned substrates were subsequently pre-treated with stannous chloride sensitizer and palladiun chloride activator.

Copper coating was achieved by electroless method using a copper bath. Electroplating of copper should be resorted to for further increase in thickness if required. One can use electroless method to deposit copper for good adhesion, uniformity and smoothness. This approach is least expensive and reliable. The characteristics of copper-coated PTFE for microwave devices are that the dielectric constant is around 2.2 and the dissipation factor is $0.000 t$.

\section{Conclusions}

Considering the strategic role enjoyed by microwave technology in aerospace and communications, the demand for materials with more specific characteristics will increase, especially for miniaturized microwave systems. Ferroelectric thin films can also get a renewed interest. Temperature-compensated dielectrics can also be used as MIC substrates. Properties of high temperature superconductors are being exploited for various microwave applications. Materials with low loss and high $\mathrm{c}$ are required for developing MICs in the lower microwave frequencies. Overcrowding of microwave frequencies and the special characteristics of millimeter waves force more and more systems to operate in the millimeter range, which requires materials with low dielectric constant and low loss at high frequencies.

\section{References}

Baba P D, Argentina G M, Courtney W E, Dionne G F and Temme D 1971 JEEE Trans. Magnet. $735 \mathrm{I}$ Courtney W E 1970 IEEE Trans. Microwase Th. Tech. MTT 18476

Das R 1967 Solid State Electron. 10857

Das S N 1964 1EEE Trans. Microwave Th. Tech 12440

Fiedziszko J S 1986 Mlcrowave J. 189

Horton J B ard Donaldson M R 1967 IEEE Trans. Microwave Th. Tech, 15517

Lires and Glass 1977 Principles and applications of ferroelectrics and related materials (Oxford: Clarendon Press)

Murthy Y R K ard Raman R 1989 Sold Stata Commun. 70847

Nomura $S 1983$ Ferroelectrics 4961

Olyphant M and Bell J H 1970 IEEE Trans. Elect, Insul. E1-5 26

Subba Rao T, Murthy V R K and Viswanathan B 1990 Ferroelectrics 102155

Trutt R O 1980 Microwave J. 2347

Wakiro K, Mina: K and Tamura H 1984 J. Am. Ceram. Soc. 67278

Weermbke \& D 1979 Microwaves 1866 